\title{
Predictability of persistent frequent attendance: a historic 3-year cohort study
}

\author{
Frans ThM Smits, Henk J Brouwer, Henk CP van Weert, Aart H Schene and Gerben ter Riet
}

\author{
ABSTRACT \\ Background \\ Few patients who attend GP consultations frequently \\ continue to do so long term. While transient frequent \\ attendance may be readily explicable, persistent \\ frequent attendance often is not. It increases GPs' \\ workload while reducing work satisfaction. It is neither \\ reasonable, nor efficient to target diagnostic \\ assessment and intervention at transient frequent \\ attenders. \\ Aim \\ To develop a prediction rule for selecting persistent \\ frequent attenders, using readily available information \\ from GPs' electronic medical records. \\ Design of study \\ A historic 3-year cohort study.

\section{Method} \\ Data of 28860 adult patients from 2003 to 2005 were \\ examined. Frequent attenders were patients whose \\ attendance rate ranked in the (age- and sex-adjusted) \\ top $10 \%$ during 1 year (1-year frequent attenders) or \\ 3 years (persistent frequent attenders). Bootstrapped \\ multivariable logistic regression analysis was used to \\ determine which predictors contained information on \\ persistent frequent attendance. \\ Results \\ Of 3045 1-year frequent attenders, 470 (15.4\%) \\ became persistent frequent attenders. The prediction \\ rule could update this prior probability to $3.3 \%$ (lowest \\ value) or $43.3 \%$ (highest value). However, the 10th and \\ 90th centiles of the posterior probability distribution \\ were $7.4 \%$ and $26.3 \%$ respectively, indicating that the \\ model performs modestly. The area under the receiver \\ operating characteristic curve was 0.67 (95\% \\ confidence limits 0.64 and 0.69 ).

\section{Conclusion} \\ Among 1-year frequent attenders, six out of seven are \\ transient frequent attenders. With the present \\ indicators, the rule developed performs modestly in \\ selecting those more likely to become persistent \\ frequent attenders. \\ Keywords \\ cohort study; frequent attender; family practice; menta \\ disorders; prognosis; staff workload.
}

\section{INTRODUCTION}

It is estimated that about $80 \%$ of a GPs' clinical work is spent on $20 \%$ of their patients, and that one in every seven consultations is with patients who rank in the top $3 \%$ of the attendance rate. ${ }^{1}$ Frequent attendance is often defined as an age- and sexadjusted attendance rate ranking in the top $10 \%$ within a time frame of 1 year. ${ }^{2,3}$

Although longitudinal studies on frequent attenders are scarce, it is known that most frequent attenders frequently attend their GP for a short period of time only. ${ }^{4-7}$ It is neither reasonable, nor efficient to target extensive diagnostic assessment, monitoring, and intervention at transient 1-year frequent attenders. However, the issue of patients who continue to attend frequently requires attention, and potential interventions should be targeted at this group.

Trials on the effect of (mainly psychiatric) interventions on morbidity and attendance rates have shown conflicting results. ${ }^{8}$ No study showed convincing evidence that an intervention improves

FThM Smits, MD, GP; HJ Brouwer, psychologist, coordinator Network of General Practitioners of the Academic Medical Centre/University of Amsterdam; HCPM van Weert, MD, PhD, GP, associate professor of general practice, Division of Clinical Methods and Public Health, Department of General Practice, Academic Medical Centre; AH Schene, MD, PhD, professor of psychiatry, Department of Psychiatry, Academic Medical Centre; G ter Riet, MD, PhD, associate professor, clinical epidemiologist, Division of Clinical Methods and Public Health, Department of General Practice, Academic Medical Centre, University of Amsterdam, The Netherlands; Horten Zentrum, University of Zürich, Zürich, Switzerland.

Address for correspondence

Frans ThM Smits, Department of General Practice, Academic Medical Centre, University of Amsterdam, PO Box 22700, 1100 DE Amsterdam, the Netherlands. E-mail: F.T.Smits@amc.uva.nl

Submitted: 21 April 2008; Editor's response: 12 June 2008; final acceptance: 27 August 2008.

(c)British Journal of General Practice

This is the full-length article of an abridged version published in print. Cite this article as: Br J Gen Pract 2009; DOI: 10.3399/bjgp09X395120. 
quality of life or morbidity of frequent-attending primary care patients, although an effect might exist in a subgroup of depressed frequent attenders. ${ }^{9-11}$ For this subgroup, one trial concluded that, in the year following the intervention, patients in the intervention group had a mean of 47 more depression-free days (5\% confidence interval $[\mathrm{Cl}]=27$ to 68 ) than patients with depression who received no intervention. ${ }^{11}$ There is no evidence that it is possible to influence healthcare utilisation of frequent attenders. All trials except one included patients that attended frequently during 1 year. ${ }^{12}$

Using information that was readily available in GPs' electronic medical records, this study set out to develop a prediction rule to help GPs to identify, among 1-year frequent attenders, those at extremely low or high risk of becoming persistent frequent attenders. Such a rule, in addition to being clinically useful, may also support the selection of more homogeneous patient groups in future randomised trials among (subgroups of) persistent frequent attenders.

\section{METHOD}

\section{Patient population}

Five primary healthcare centres in Amsterdam provided data for this study. These centres participate in the GP-based continuous morbidity registration network of the Department of General Practice, Academic Medical Centre, University of Amsterdam. In this network, electronic medical record data are extracted for research purposes. The studied patients have a lower socioeconomic level, are of more non-western descent, and are slightly younger than the Dutch population. The participating GPs use a problem-oriented registration method. This study used the numbers of face-to-face consultations with the GPs, the lists of current medical problems as registered and coded by the GP using the International Classification of Primary Care (ICPC), and the number of a selection of prescriptions of all patients from 1 January 2003 to 31 December 2005.

\section{Selection of 1-year frequent attenders and persistent frequent attenders}

Frequent attenders were defined as those patients whose attendance rate ranked nearest to the top 10th centile of their sex and age group (15-30, $31-45,46-60$, and $\geq 61$ years). ${ }^{2,3}$ Frequent attenders were determined for each of the years 2003, 2004, and 2005. The selected frequent attenders of 2003 were taken as a starting point. Persistent frequent attenders were defined as those patients who were both registered and frequent attenders during all 3 years.

\section{How this fits in}

Frequent attending has been studied extensively, but is mostly not persistent. Little is known about persistent frequent attendance, but potential interventions should be targeted at this group. A rule was developed to predict which

frequent attenders will persist in this behaviour. Using information that was

readily available from the GPs' electronic medical record, it was only possible to update the prior probability modestly.

Only face-to-face consultations with GPs (consultations in the office and house calls) were included. Consultations with other practice staff were excluded because these contacts are mostly initiated by GPs or their staff, and are related to controlling chronic diseases. Mean number of consultations per age and sex group was determined for frequent attenders and non-frequent attenders. Patients younger than 15 years were excluded, because their consultations often depend on their parents.

\section{Definition and extraction of predictor information}

In the problem-oriented approach to medical record keeping, a patient may have a list of current medical problems, also called a problem list. In the Netherlands, a current medical problem is defined by the GP as:

- any medical problem (disease or complaint) which needs continuing medical attention or monitoring; or

- any complaint or disease present for more than 6 months (excluding all (minor) short episodes).

Every problem on this list was coded by the GPs using the ICPC. ${ }^{13}$ Problem lists were extracted at the end of 2003 and 2005. The prevalence of each medical problem was calculated for 1-year frequent attenders at the end of the first year, and for persistent frequent attenders at the end of the third year. The electronic medical record was used to extract those prescriptions and medical problems in which, according to the literature, frequent attenders and non-frequent attenders differed most: number of prescriptions (for analgesics, tranquillisers, antidepressants, and antibiotics), diabetes mellitus, chronic cardiovascular disease, chronic respiratory disease, (feelings of) anxiety, (feelings of) depression, addictive behaviour, any psychological/psychiatric problem, all social problems, and medically unexplained physical symptoms (MUPS)..$^{3,14}$ MUPS were defined according to Robbins et al and complied with the definition of the problem list. ${ }^{15}$ (See Appendix 1 for the ICPC codes used.) 


\section{Box 1. Approach to the multivariable analysis.}

Loss to follow-up

A total of $365(12 \%)$ were lost at some point over the 2 years of follow-up. It was argued that, in theory, a potential frequent attender left the practice due to dissatisfaction with care. The resulting selection bias may attenuate associations found between predictors and frequent attendance.

The hypothesis was tested in a multivariable logistic regression analysis with an indicator variable ' 1 = left the practice' and ' $0=$ otherwise' as the dependent variable, and nine independent indicators (see below). The hypothesis was not confirmed. On the contrary, some evidence was found that those with at least one chronic somatic illness were less likely to have left the practice (odds ratio $0.73[95 \% \mathrm{Cl}=0.54$ to 0.99$]$ ); all other associations were neither strong nor significant. These results support the view that important selection bias due to moving out of practice is unlikely.

Seventy-one patients $(2.2 \%)$ had died over the 2-year follow-up period. To assess the extent to which these deaths caused selection bias (informative censoring), a sensitivity analysis was performed: (1) the entire cohort was repaired using inverse probability weighting, where the weights were derived after fitting a logistic regression model with death as the dependent variable, and (2) it was assumed that the 71 deaths were all persistent frequent attenders. ${ }^{27}$

The resulting statistics for these two additional analyses were very close to the results from the analysis in which it was assumed that those who died would not become persistent frequent attenders. Specifically, the AUCs for the additional two analyses were 0.662 (0.635 to 0.688$)$ and $0.672(0.646$ to 0.698$)$ respectively. To determine whether frequent attending is a sign of terminal disease, the analysis checked how many of the persistent frequent attenders died in the years after the analysis: of the 470 persistent frequent attenders, six died in $2006(1 \%)$, and 10 in 2007 (2.1\%).

Variable selection

Frequent attendance during all 3 years (coded as 1 , and 0 otherwise) was the dependent variable. Independent variables: continuous variables (age and the number of problems on the GP's problem list) were assessed for linear association with the dependent variable using a graphical method proposed by Harrell to avoid model mis-specification. ${ }^{28}$ The presence of diabetes mellitus and/or chronic respiratory illness and/or chronic cardiovascular illness was coded as 1; the absence of any of the above as 0 (52 had all three, 316 had two, 891 one, 1786 none). Similarly, the presence of psychological and/or social problems including (feelings of) anxiety, (feelings of) depression, and/or addictive behaviour were combined ( 0 had all five, 1 had four, 33 three, 371 two, 285 one, and 2355 none).

The use of antidepressants, anxiolytics, and/or hypnotics was similarly combined (118 patients used all three types of drugs, 290 two, 408 one, and 2107 none). Thus, the nine candidate predictors, modelled as 11 variables, were: (1) age at baseline (continuous); (2) sex; (3) number of problems on the problem list (continuous); (4) any of the three chronic somatic illnesses just mentioned (yes/no); (5) any psychological/social problem (yes/no); (6) any medically unexplained physical problem (yes/no); (7) psychoactive medication (yes/no); (8) mean monthly number of prescriptions for antibiotics ( 0 = reference category; $1-2 ;>2)$; and (9) average monthly number of prescriptions for analgesics ( 0 = reference category; $1-4 ;>4)$.

A final model was selected using bootstrapped forward stepwise logistic regression analysis which was performed 100 times. $^{29}$ The $P$-values for entry of variables into and removal from the model were 0.10 and 0.15 respectively. Candidate predictors had to be selected 70 times or more to be eligible for the final model. The final model's fit was tested using the Hosmer-Lemeshow test (10 groups), and accounted for intracluster correlation within general practices by using robust variance estimation according to Huber and White. ${ }^{30}$

Adding interaction terms to the final model, subgroup effects were assessed in the following subgroups, requiring a $P$-value $<0.10$ for significance: co-existence of a documented somatic and psychosocial problem; co-existence of a psychosocial problem and prescription of pain medication; female sex and prescription of pain medication. The regression coefficients of the final model were used to calculate the probabilities of being a persistent frequent attender. The final model's AUC ROC was calculated as a summary of predictive power. The final model was fitted 500 times using bootstrap methodology, and the corresponding ROC curves were used to construct a more robust confidence interval around the AUC, thus counteracting the influence of observations unique to the study's dataset.

$A U C=$ area under curve. $R O C=$ receiver operating characteristic.

\section{Statistical analysis}

A multivariable analysis was applied using all the above-mentioned information as predictors for persistence of frequent attendance (Box 1). After checks for errors and consistency, the potential for selection bias due to loss to follow-up and death was assessed, and bootstrapped stepwise logistic regression was used to select the variables for the 


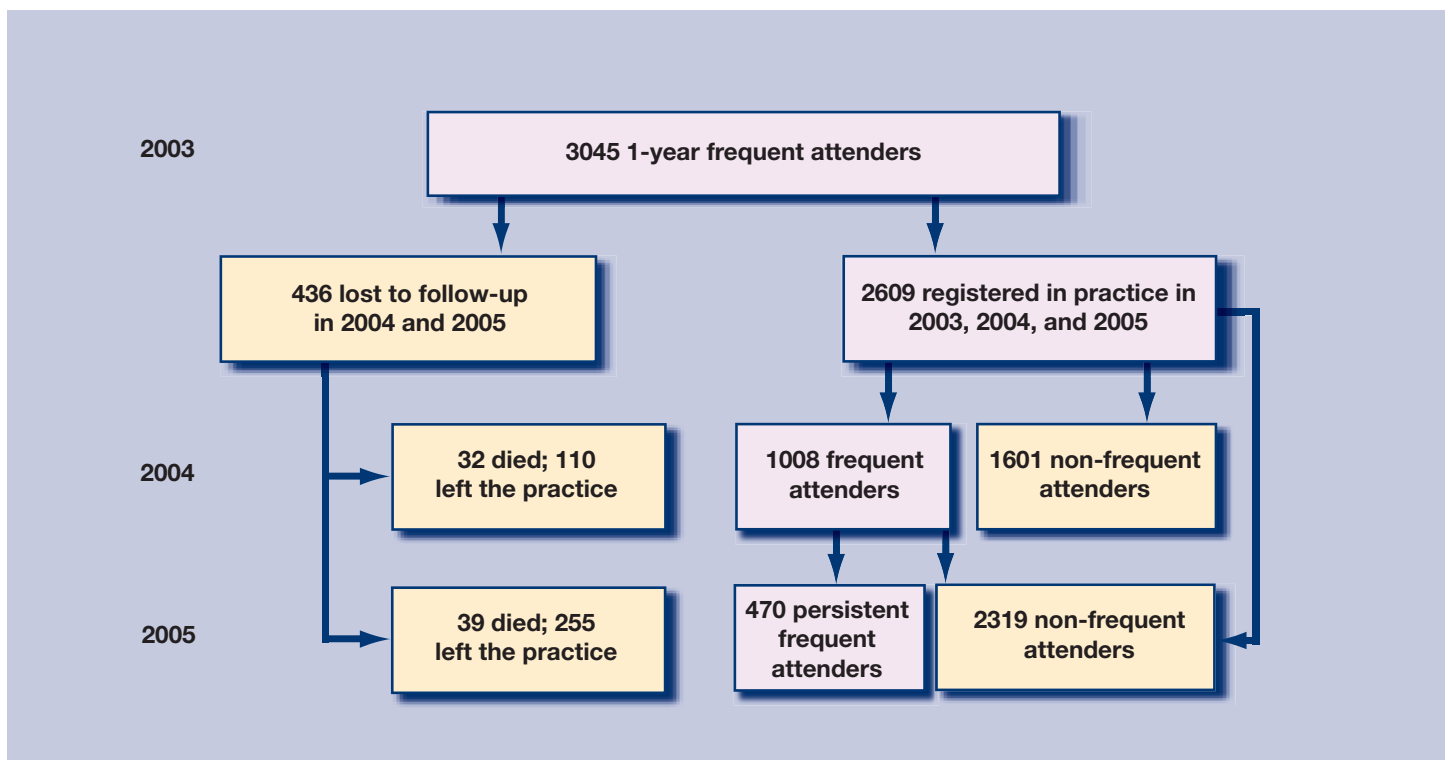

Figure 1. Flow diagram of persistence of frequent attendance over 3 years.

final model.

Box 1 provides a detailed description of the analytical approach. Statistical analyses were performed in Stata (version 9.2).

\section{RESULTS}

\section{Persistent frequent attenders}

Of the 2609 frequent attenders in 2003 who could be followed for 3 years, 1008 (38.6\%) also frequently attended in 2004, while 470 (18.0\%) continued to do so in 2004 and 2005 and were therefore considered persistent frequent attenders according to the study definition (Figure 1). These persistent frequent attenders comprised $1.6 \%$ of all registered patients aged $\geq 15$ years in 2003. Selection bias was studied, but almost no bias was found for moving out of practice or for death (Box 1).

\section{Prediction of persistent frequent attendance}

Table 1 shows the univariate associations of all candidate predictors with the dependent variable: persistent frequent attendance. Five predictors were retained in the final model: age, the number of problems on the GP's problem list, presence of any of three chronic somatic illnesses (diabetes mellitus, cardiovascular illness, and respiratory illness), presence of a psychological/social problem, and the use of pain medication (Table 2). None of the interaction effects proved significant at the $10 \%$ level. The prior probability of $15.4 \%$ (470/3045) of persistent frequent attendance could be updated, using the model, to at best $3.3 \%$ (lowest value) or $43.3 \%$ (highest value). The 10th and 90th centiles of the posterior probability distribution were $7.4 \%$ and $26.3 \%$ respectively, indicating that the model does not perform very well either to rule out persistent frequent attendance or to rule it in. The Hosmer-Lemeshow test showed a $P$-value of 0.254 , thus indicating no strong evidence against good model fit. As a summary of the model's overall discrimination, the model's area under the receiver operating characteristic curve (AUC ROC) was 0.67 (bootstrapped bias-corrected $95 \% \mathrm{Cl} 0.64$ to 0.69 ).

\section{DISCUSSION}

\section{Summary of main findings}

In a historic 3-year cohort study, it was found that $15.4 \%$ of all 1 -year frequent attenders persisted in this behaviour during 2 consecutive years. Persistent frequent attenders constituted less than $2 \%$ of all

Table 1. Univariate associations of candidate predictors with the dependent variable: persistent frequent attendance. ${ }^{\mathrm{a}}$

\begin{tabular}{lcc} 
Predictor & (Crude) odds ratio & $95 \% \mathrm{Cl}$ \\
\hline Age $^{\text {b }}$ & 1.01 & 1.00 to 1.017 \\
\hline Sex, female & 1.46 & 1.14 to 1.87 \\
\hline Number of active problems $^{\text {b }}$ & 1.21 & 1.16 to 1.25 \\
\hline Any chronic somatic illness $^{\prime}$ & 1.97 & 1.67 to 2.33 \\
\hline Any psychological problem & 2.18 & 1.73 to 2.76 \\
\hline Medically unexplained complaint & 2.02 & 1.55 to 2.62 \\
\hline Any psychoactive medication & 1.50 & 1.21 to 1.86 \\
\hline Mean monthly number of analgesic prescriptions & \\
0 & 1.00 & Reference category \\
$1-4$ & 1.83 & 1.48 to 2.25 \\
$>4$ & 2.56 & 1.98 to 3.30 \\
\hline Mean monthly number of antibiotic prescriptions & \\
0 & 1.00 & Reference category \\
$1-2$ & 1.21 & 0.99 to 1.48 \\
$>2$ & 1.46 & 0.98 to 2.18 \\
\hline
\end{tabular}

a3045 observations; 470 persistent frequent attenders (dependent variable $=1$ ). ${ }^{b}$ Modelled as a continuous variable; all other variables were modelled as dummies. 


\section{Table 2. Associations between the five predictors retained in the final model and the dependent variable: persistent frequent attendance. ${ }^{a}$}

\begin{tabular}{lcc} 
Predictor & (Adjusted) odds ratio & $95 \% \mathrm{Cl}$ \\
\hline Age $^{\mathrm{b}}$ & 0.99 & 0.98 to 1.00 \\
\hline Number of active problems $^{\mathrm{b}}$ & 1.13 & 1.05 to 1.22 \\
\hline Any chronic somatic illness & 1.55 & 1.25 to 1.93 \\
\hline Any psychological problem & 1.72 & 1.30 to 2.27 \\
\hline Mean monthly number of analgesic prescriptions & \\
0 & 1 & Reference \\
$1-4$ & 1.77 & 1.41 to 2.23 \\
$>4$ & 2.06 & 1.59 to 2.66 \\
\hline
\end{tabular}

a Based on 3045 observations; 470 persistent frequent attenders (dependent variable $=1$ ). ${ }^{b}$ Modelled as a continuous variable; all other variables were modelled as dummies.

registered patients aged $\geq 15$ years. It proved difficult, using information that is currently readily available from GPs' electronic medical records, to predict which 1-year frequent attenders will persist in frequent consulting behaviour.

\section{Strength and limitations of the study}

An important strength of this study is the size and the longitudinal character of the dataset, and the experience of the participating GPs in recording and coding the problem lists. Most GPs have participated in the registration network for over 10 years and are used to feedback on their registration activity. The problem lists have been monitored over the years, and differences between doctors have been regularly discussed. ${ }^{16}$ Prescriptions are extracted from the electronic medical record and reflect the number of actual prescriptions. Prescription data in general practice may be generally considered to be of higher quality than diagnosis-oriented data. ${ }^{17}$ The present study was based on routinely collected data reflecting everyday general practice in the Netherlands. As far as the authors are aware, this study is the first to use information readily available to GPs to predict persistence of frequent attendance.

Routine data that are readily available have their limitations; for example, problem lists may be inflated (by not removing resolved problems) or subject to under-reporting. Moving out of practice was a reason for exclusion, as follow-up of these patients was not possible. Unfortunately, ethnicity and socioeconomic level are not (sufficiently) registered in the current electronic medical record. This precluded an analysis of the interaction between ethnicity and several other predictors to explore the role of ethnicity in more detail.

\section{Comparison with existing literature}

There is substantial literature about the characteristics and morbidity of frequent attenders. ${ }^{3,14}$ It is striking that almost all descriptive literature about frequent attendance is produced in countries with some kind of list system: UK, Scandinavian countries, and health maintenance organisations in the US. ${ }^{3,14}$ Most research on frequent attenders, however, is cross-sectional and uses 1-year attendance rates. In particular, 1-year frequent attenders have been reported to use more analgesics, more antibiotics, and more tranquillisers. ${ }^{18,19}$ High attendance rates are also found for patients with medically unexplained somatic symptoms, health anxiety, and perceived poor health..$^{20-22}$ The few longitudinal studies show attendance rates regress to the mean over time, with only $20-30 \%$ of frequent attenders continuing to attend frequently in the following year. ${ }^{4-7}$ However, these studies of persistent frequent attendance use different definitions of frequent attenders and lack the power to detect factors associated with transient frequent attendance becoming persistent. In one study, psychological distress, as measured with two psychometric scales, was found to increase the risk of future daytime frequent attendance of adult patients in family practice..$^{23}$ As frequent attendance proves to be mostly a transient problem, interventions in 1year frequent attenders do not seem worthwhile.

Several trials have been conducted to test interventions to change consultation behaviour and/or morbidity of frequent attenders. ${ }^{8}$ Only one study examined frequent attendance over 2 years; ${ }^{10,11}$ all others included 1-year frequent attenders. ${ }^{24-26}$ Although none of the studies found evidence that it is possible to influence healthcare utilisation by frequent attenders, the one that included frequent attenders over 2 years did find evidence that treatment of major depressive disorder in a subgroup of depressed frequent attenders improved their symptoms and quality of life..$^{10,11}$

\section{Implications for future research}

From the viewpoint of delivering good care, GPs have neither a reason nor the instruments to look for unmet healthcare needs among 1-year frequent attenders. Both psychological and somatic chronic diseases and complaints modestly predispose a 1year frequent attender to become a persistent frequent attender. However, as the predictive power (for inclusion as well as for exclusion) of the rule developed in this study proved to be small, there might be other reasons for persistence of frequent attendance.

Because this study was not a prospective cohort study, the existence of 'hidden morbidity' among persistent frequent attenders cannot be excluded. 
Further studies are needed to decide, first, whether there exists undiscovered morbidity among persistent frequent attenders and, secondly, whether it is possible and worthwhile to construct a rule with sufficient performance for risk stratification by using more information about the patient or from diagnostic tests.

In conclusion, among 1-year frequent attenders, about six out of seven are transient frequent attenders. Information from GPs' electronic medical records may be used to identify those at low and higher risk of becoming persistent frequent attenders. With the present indicators available in the electronic medical record, the rule developed performs modestly in selecting those at risk of becoming persistent frequent attenders.

\section{Funding body}

Stichting steunfonds medische en sociale dienstverlening Reigersbos. (Foundation to support medical and social services Reigersbos.) Part of this study was financed by a grant from the Netherlands Organization for Health Research and Development (ZonMw), programme Mental Health (100.002.001)

\section{Ethical approval}

According to the Medical Research Involving Human Subjects Act (WMO), formal approval for this research project by a medical ethics committee was not necessary. The academic GP network extracts data according to strict guidelines for the privacy protection of patients and GPs. In addition we sought and obtained permission for this work from the board of the network

\section{Competing interests}

The authors have stated that there are none

\section{Acknowledgements}

We thank the GPs involved in the Network of General Practitioners of the Academic Medical Centre/University of Amsterdam (HAG-net-AMC) for their continuous efforts to keep the electronic medical records updated.

\section{Discuss this article}

Contribute and read comments about this article on the Discussion Forum: http://www.rcgp.org.uk/bjgp-discuss

\section{REFERENCES}

1. Neal RD, Heywood PL, Morley S, et al. Frequency of patients' consulting in general practice and workload generated by frequent attenders: comparisons between practices. Br J Gen Pract 1998; 48(426): 895-898.

2. Smits FT, Mohrs JJ, Beem EE, et al. Defining frequent attendance in general practice. BMC Fam Pract 2008; 9(1): 21.

3. Vedsted $P$, Christensen MB. Frequent attenders in general practice care: a literature review with special reference to methodological considerations. Public Health 2005; 119(2): 118-137.

4. Ward AM, Underwood P, Fatovich B, Wood A. Stability of attendance in general practice. Fam Pract 1994; 11(4): 431-437.

5. Botica MV, Kovacic L, Tiljak MK, et al. Frequent attenders in family practice in Croatia: retrospective study. Croat Med J 2004; 45(5): 620-624.

6. Carney TA, Guy S, Jeffrey G. Frequent attenders in general practice: a retrospective 20-year follow-up study. Br J Gen Pract 2001; 51(468): $567-569$.
7. Andersson S-O, Lynoe N, Hallgren C-G, Nilsson M. Is frequent attendance a persistent characteristic of a patient? Repeat studies of attendance pattern at the family practitioner. Scand J Prim Health Care 2004; 22(2): 91-94.

8. Smits FT, Wittkampf KA, Schene AH, et al. Interventions on frequent attenders in primary care. A systematic literature review. Scand J Prim Health Care 2008; 26(2): 111-116.

9. Schreuders B, van MH, Smit J, et al. Primary care patients with mental health problems: outcome of a randomised clinical trial. $\mathrm{Br} J$ Gen Pract 2007; 57(544): 886-891.

10. Simon GE, Manning WG, Katzelnick DJ, et al. Cost-effectiveness of systematic depression treatment for high utilizers of general medical care. Arch Gen Psychiatry 2001; 58(2): 181-187.

11. Katzelnick DJ, Simon GE, Pearson SD, et al. Randomized trial of a depression management program in high utilizers of medical care. Arch Fam Med 2000; 9(4): 345-351.

12. Smits FTM, Wittkampf KA, Schene A, et al. Interventions on frequent attenders in primary care. A systematic literature review. Scand J Prim Health Care 2008; 26(2): 111.

13. Lamberts $\mathrm{H}$, Wood M. International classification of primary care. Oxford: Oxford University Press, 1988.

14. Gill D, Sharpe M. Frequent consulters in general practice: a systematic review of studies of prevalence, associations and outcome. J Psychosom Res 1999; 47(2): 115-130.

15. Robbins JM, Kirmayer LJ, Hemami S. Latent variable models of functional somatic distress. J Nerv Ment Dis 1997; 185(10): 606-615.

16. Brouwer HJ, Bindels PJ, Weert HC. Data quality improvement in general practice. Fam Pract 2006; 23(5): 529-536.

17. Thiru K, Hassey A, Sullivan F. Systematic review of scope and quality of electronic patient record data in primary care. BMJ 2003; 326(7398): 1070 .

18. Bergh H, Marklund B. Characteristics of frequent attenders in different age and sex groups in primary health care. Scand J Prim Health Care 2003; 21(3): 171-177.

19. Vedsted P, Sorensen HT, Mortensen JT. Drug prescription for adult frequent attenders in Danish general practice: a population-based study. Pharmacoepidemiol Drug Saf 2004; 13(10): 717-724.

20. Little P, Somerville J, Williamson I, et al. Psychosocial, lifestyle, and health status variables in predicting high attendance among adults. Br J Gen Pract 2001; 51(473): 987-994.

21. Verhaak PF, Meijer SA, Visser AP, Wolters G. Persistent presentation of medically unexplained symptoms in general practice. Fam Pract 2006; 23(4): 414-420.

22. de Waal MW, Arnold IA, Eekhof JA, et al. Follow-up study on health care use of patients with somatoform, anxiety and depressive disorders in primary care. BMC Fam Pract 2008; 9(1): 5 .

23. Vedsted P, Fink P, Olesen F, Munk-Jorgensen P. Psychological distress as a predictor of frequent attendance in family practice: a cohort study. Psychosomatics 2001; 42(5): 416-422.

24. Christensen MB, Christensen B, Mortensen JT, Olesen F. Intervention among frequent attenders of the out-of-hours service: a stratified cluster randomized controlled trial. Scand J Prim Health Care 2004; 22(3): 180-186.

25. Katon W, Von KM, Lin E, et al. A randomized trial of psychiatric consultation with distressed high utilizers. Gen Hosp Psychiatry 1992; 14(2): 86-98.

26. Olbrisch ME. Evaluation of a stress management program for high utilizers of a prepaid university health service. Med Care 1981; 19(2): 153-159.

27. Hernan MA, Hernandez-Diaz S, Robins JM. A structural approach to selection bias. Epidemiology 2004; 15(5): 615-625.

28. Harrell F. Regression modeling strategies. New York: Springer, 2001.

29. Sauerbrei W, Schumacher M. A bootstrap resampling procedure for model building: application to the Cox regression model. Stat Med 1992; 11(16): 2093-2109.

30. Williams RL. A note on robust variance estimation for clustercorrelated data. Biometrics 2000; 56(2): 645-646. 
FThM Smits, HJ Brouwer, HCP M van Weert, et al

Appendix 1. Selected problems and diseases with ICPC codes.

\begin{tabular}{|c|c|c|c|}
\hline $\begin{array}{l}\text { Prevalence } \\
(n / 1000,\end{array}$ & $\begin{array}{l}\text { at end of first year } \\
\geq 15 \text { years of age) }\end{array}$ & ICPC code & Problem \\
\hline Diabetes & 60.3 & T90 & Diabetes mellitus type 1 and 2 \\
\hline Chronic cardiovascular disease & $\begin{array}{c}14.6 \\
10.5 \\
6.1 \\
6.6 \\
8.1 \\
0.1 \\
7.6 \\
78.6 \\
16.8 \\
5.5 \\
10.2 \\
1.6 \\
8.1\end{array}$ & $\begin{array}{l}\text { K74 } \\
\text { K75 } \\
\text { K76 } \\
\text { K77 } \\
\text { K78 } \\
\text { K82 } \\
\text { K83 } \\
\text { K86 } \\
\text { K87 } \\
\text { K89 } \\
\text { K90 } \\
\text { K91 } \\
\text { K92 }\end{array}$ & $\begin{array}{c}\text { Angina pectoris } \\
\text { Acute myocardial infarction } \\
\text { Other and chronic ischaemic heart disease } \\
\text { Heart failure } \\
\text { Atrial fibrillation/flutter } \\
\text { Pulmonary heart disease } \\
\text { Heart valve disease NOS, non-rheumatoid } \\
\text { Hypertension, uncomplicated } \\
\text { Hypertension with involvement of target organs } \\
\text { Transient cerebral ischaemia } \\
\text { Cerebrovascular accident; stroke } \\
\text { Atherosclerosis excluding heart/brain } \\
\text { Other arterial obstruction/peripheral vascular disease }\end{array}$ \\
\hline Chronic respiratory problems & $\begin{array}{c}0.7 \\
2.4 \\
16.8 \\
40.9 \\
49.3 \\
\end{array}$ & $\begin{array}{l}\text { R70 } \\
\text { R91 } \\
\text { R95 } \\
\text { R96 } \\
\text { R97 }\end{array}$ & $\begin{array}{c}\text { Tuberculosis respiratory/nos } \\
\text { Chronic bronchitis/bronchiectasis } \\
\text { Emphysema/chronic obstructive pulmonary disease } \\
\text { Hay fever, asthma } \\
\text { Allergic rhinitis }\end{array}$ \\
\hline 2. (Feelings of) depression & $\begin{array}{c}109.7 \\
5.8 \\
11.0 \\
0.3 \\
0.7 \\
0.8 \\
0 \\
0 \\
0.9 \\
0 \\
0 \\
0.2 \\
0 \\
0 \\
0 \\
0.2 \\
2.1 \\
29.0 \\
8.1 \\
0.5 \\
1.0 \\
1.9 \\
3.2 \\
\end{array}$ & $\begin{array}{l}\text { All P } \\
\text { P01 } \\
\text { P74 } \\
\text { P09 } \\
\text { A-Y27 } \\
\text { A-D26 } \\
\text { L26 } \\
\text { N26 } \\
\text { R-Y26 } \\
\text { A25 } \\
\text { B25 } \\
\text { K24 } \\
\text { K25 } \\
\text { X23/Y25 } \\
\text { X24/Y24 } \\
\text { X25 } \\
\text { P03 } \\
\text { P76 } \\
\text { P15 } \\
\text { P16 } \\
\text { P17 } \\
\text { P18 } \\
\text { P19 }\end{array}$ & $\begin{array}{c}\text { All psychological/psychiatric codes } \\
\text { Feeling anxious/nervous/tense } \\
\text { Anxiety disorder/anxiety state } \\
\text { Concern about sexual preference } \\
\text { Fear of other disease of ... } \\
\text { Fear of cancer of ... } \\
\text { Fear of cancer musculoskeletal tract } \\
\text { Fear of cancer of neurological system } \\
\text { Fear of cancer of ... system } \\
\text { Fear of death } \\
\text { Fear of AlDS } \\
\text { Fear of heart attack } \\
\text { Fear of hypertension } \\
\text { Fear of venereal disease } \\
\text { Fear of sexual dysfunction } \\
\text { Fear of genital cancer } \\
\text { Feeling depressed } \\
\text { Depressive disorder } \\
\text { Chronic alcohol abuse } \\
\text { Acute alcohol abuse } \\
\text { Tobacco abuse } \\
\text { Medicinal abuse } \\
\text { Drug abuse }\end{array}$ \\
\hline Social problems & 15.6 & All Z & All socioeconomic problems \\
\hline $\begin{array}{l}\text { Medically unexplained } \\
\text { physical problems }\end{array}$ & $\begin{array}{c}4.1 \\
2.7 \\
18.0 \\
1.8 \\
0.8 \\
3.9 \\
4.8 \\
2.3 \\
2.1 \\
2.1 \\
0 \\
0 \\
0.3 \\
0 \\
0.4 \\
0.5 \\
2.3 \\
0.5 \\
1.1 \\
0 \\
0.4 \\
0 \\
3.4 \\
1.9 \\
10.7\end{array}$ & $\begin{array}{l}\text { L01 } \\
\text { L02 } \\
\text { L03 } \\
\text { L04 } \\
\text { L18 } \\
\text { N01 } \\
\text { N02 } \\
\text { A04 } \\
\text { P06 } \\
\text { P20 } \\
\text { T03 } \\
\text { T07 } \\
\text { T08 } \\
\text { P04 } \\
\text { R02 } \\
\text { K04 } \\
\text { N17 } \\
\text { R21 } \\
\text { N06 } \\
\text { D09 } \\
\text { D11 } \\
\text { D08 } \\
\text { D12 } \\
\text { D01 } \\
\text { D93 }\end{array}$ & $\begin{array}{c}\text { Neck symptoms/complaints (excluding headache) } \\
\text { Back symptoms/complaints } \\
\text { Low back complaints without radiation } \\
\text { Chest symptoms/complaints } \\
\text { Muscle pain/fibrositis } \\
\text { Headache } \\
\text { Tension headache } \\
\text { General weakness/tiredness } \\
\text { Disturbance of sleep/insomnia } \\
\text { Disturbance of memory, concentration } \\
\text { Loss of appetite } \\
\text { Weight gain } \\
\text { Weight loss } \\
\text { Feeling irritable/behaving irritably } \\
\text { Shortness of breath, dyspnoea } \\
\text { Palpitations/aware of heartbeat } \\
\text { Vertigo/dizziness } \\
\text { Symptoms/complaints of the throat } \\
\text { Nausea } \\
\text { Diarrhoea/loose bowels } \\
\text { Other sensation disturbance/abormal involuntary movements } \\
\text { Constipation } \\
\text { Generalised abdominal pain/cramps } \\
\text { Irritable bowel syndrome }\end{array}$ \\
\hline
\end{tabular}

ICPC = International Classification of Primary Care. NOS = not otherwise specified. 